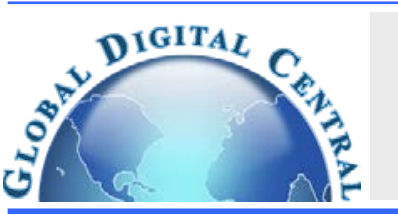

Frontiers in Heat and Mass Transfer

Available at www.ThermalFluidsCentral.org

\title{
EXPERIMENTAL INVESTIGATION ON HEAT TRANSFER AND FRICTION FACTOR CHARACTERISTICS OF A STATIONARY SQUARE DUCT ROUGHENED BY V AND A-SHAPED RIBS
}

\author{
Anand Shukla ${ }^{\mathrm{a}}$, Alok Chaube ${ }^{\mathrm{b}}$, Shailesh Gupta ${ }^{\mathrm{c}}$ and Arvind Sirsath ${ }^{\mathrm{c}}$ \\ ${ }^{a}$ Faculty of Engineering \& Technology, Mahatma Gandhi Chitrakoot Gramodaya, Vishwavidyalaya, Satna-485331,India \\ ${ }^{b}$ Department of Mechanical Engineering, Jabalpur Engineering College, Jabalpur-482011, India \\ ${ }^{c}$ Department of Mechanical Engineering, Hitkarini College of Engineering \& Technology, Jabalpur-482005, India
}

\section{ABSTRACT}

One of the traditional methods used to improve the efficiency of a gas turbine is to increases the inlet temperature; thereby increasing the power output and in turn, the efficiency. The internal cooling passages of blades are roughened by artificial roughness to improve the cooling performance. The present study investigates the convective heat transfer and friction factor (pressure drop) characteristics of a rib-roughened square duct. The test section of the duct is roughened on its top and bottom wall with $\mathrm{V}$ and $\Lambda$ - shaped square ribs. In the study, the Reynolds number ( $R e$ ) varied from 10,000 to 40,000 , the relative roughness height $\left(e / \mathrm{D}_{\mathrm{h}}\right)$ is 0.060 , relative roughness pitch $(p / e)$ is 10 and rib attack angle $(\alpha)$ is taken as $45^{\circ}$ and $60^{\circ}$. The comparison of heat transfer and pressure drop for $\mathrm{V}$ and $\Lambda$ - shaped ribs is presented in the form of Nusselt Number and friction factor. The results show that the Nusselt number enhancement decreases when the Reynolds number increases. The friction factor ratio is found to increases as Reynolds number increases. The thermal performance decreases when the Reynolds number increases. It seems that the ribs disturb the main flow resulting in the recirculation and secondary flow near the ribbed wall. The heat transfer coefficient and friction factor for all the cases are higher than that of the smooth duct. The V-shaped ribs have higher Nusselt number and friction factor than the $\Lambda$ - shaped ribs. It is also concluded that the $\mathrm{V}$-shaped ribs perform better than the $\Lambda$ - shaped ribs. Ribs with $\alpha=60^{\circ}$ produces higher heat transfer and friction factor than $\alpha=45^{\circ}$. The results obtained in the study will help the turbine blade designer to design the effective cooling methods to cool the blades.
\end{abstract}

Keywords: Friction factor; Nusselt number; Reynolds number; thermal performance, V-shaped ribs.

\section{INTRODUCTION}

It has been made to apply different active and passive methods of heat transfer enhancement in rectangular / square ducts which can be used in compact heat exchangers for the automotive industry, air-conditioning and refrigerant applications, internal cooling for gas turbine blades, electrical circuits in electronic chipsets, etc. Achieving higher heat transfer rates through various augmentation techniques can result in substantial energy savings, more compact and less expensive apparatus with higher thermal efficiency. One of the methods to enhance the heat transfer in a flow passage is to roughen the surfaces with ribs which is popularly used in the design of internal cooling passage of turbine blade. The surfaces roughened with the ribs cause extra flow resistances. Hence to optimize the shape and orientation of ribroughened surface, it is required to investigate the heat transfer and friction characteristics of various roughened surfaces.

The performance of the heat transfer surface with ribs depends significantly on the parameters of the flow structure, such as reattachment length of the separated streamline and turbulence intensities, as well as the area of the surface and Reynolds number. The ribs increase the level of mixing by turbulence and disturb the laminar sub-layer, also increase the surface area for convective heat transfer, thereby enhance the cooling capacity of the passage.

In general, mixing the main flow, reducing the flow boundary layer, raising the turbulent intensity, creating rotating and secondary flows are the main reasons for the increase of the heat transfer. Vortex generation is a promising technique for heat transfer augmentation. Geometrical parameters such as channel aspect ratio $(A R)$, rib height-topassage hydraulic diameter $\left(e / D_{h}\right)$, rib attack angle $(\alpha)$, rib pitch-toheight ratio $(p / e)$, rib shape, discretization of ribs and the manner in which the ribs are positioned relative to one another have considerable effects on heat transfer coefficient and friction factor of the passage (Han et al., 2001). Han et al. (1978) observed the effect of rib shape, angle of attack and pitch to rib height ratio on heat transfer and friction factor characteristics of a rectangular duct with two opposite side roughened walls. They observed that the maximum value of heat transfer and friction factor occurs for square ribs, at $p / e=10$ and $\alpha=$ $45^{\circ}$. Kiml et al. (2001) reported that the thermal performance of rib arrangements with $\alpha=60^{\circ}$ is better than that with $45^{\circ}$. Han and Park (1988) studied heat transfer and pressure losses with $90^{\circ}, 60^{\circ}, 45^{\circ}$, and $30^{\circ}$ angle ribs in square and rectangular channels. The Reynolds number was from 10000 to 60000 . They concluded that the higher thermal performance in the square channel was $30^{\circ}$ rib angle and the higher thermal performance in the rectangular channel was $45^{\circ}$ rib angle. The higher heat transfer with higher pressure drop in the square channel was $60^{\circ}$ rib angle. The square channel in their study showed a larger increase in heat transfer performance than the wide aspect ratio channels.

Lau et al. (1991) observed that the replacement of continuous transverse ribs by inclined ribs in a square duct results in higher turbulence at the ribbed wall due to interaction of the primary and secondary flows. Metzger et al. (1990) investigated the effects of rib

\footnotetext{
${ }^{\dagger}$ Corresponding author. Tel.: +919826243765, Fax.: +9107612600300,

E-mail address: gupta_shailu@rediffmail.com
} 
angle and orientation on local heat transfer in a square channel. It was found that $60^{\circ}$ angled ribs giving a two-cell pattern provided the best heat transfer performance. Lau et al. (1991) examined the turbulent heat transfer and frictional characteristics in a square channel with V-shaped ribs. The configuration investigated included $\mathrm{V}$-shaped ribs angled at $45^{\circ}, 60^{\circ}, 90^{\circ}, 120^{\circ}$ and $135^{\circ}$ for a $P / e$ ratio of 10 .The results indicated that the V-shaped ribs at $\left(\alpha=46^{\circ}\right.$ and $\left.60^{\circ}\right)$ produced a $38 \%-46 \%$ and $47 \%-66 \%$ increase in thermal performance when compared to the $90^{\circ}$ full rib. Similarly, when the following ribs were reversed, the heat transfer performance was enhanced by $26 \%-32 \%$ and $39 \%-48 \%$ respectively. This enhancement in thermal performance was accompanied by a 55\%-79\% increase in the pressure drop for various $\mathrm{V}$-shaped configurations in comparison to the $90^{\circ}$ rib. The V-shaped

ribs pointing downwards ( $\Lambda$-shaped ribs) was found to result in poor heat transfer performance. The crossed ribs whose performance was also investigated resulted in poor heat removal. It was also found that doubling the $p / e$ ratio lowers the heat transfer augmentation and friction. Liou and Hwang (1992) studied the heat transfer and flow field in the ribbed channels. They found that the $(p / e)$ of 10 resulted in the best heat transfer; the heat transfer showed a periodic behavior between consecutive ribs; and both heat transfer and friction factor increased with decreasing rib spacing. Liou and Hwang (1993) conducted experiments to measure the local as well as average heat transfer coefficients to compare the performance of square, triangular and semicircular ribs and found that the square ribs give best heat transfer performance.

It is revealed from the literature that discrete ribs were performed outstanding as compared to continuous angled or V-shaped ribs (Cho et al., 1992). It is also reviewed that $\mathrm{V}$-shaped ribs pointing upwards (Vshaped) and pointing downwards ( $\Lambda$-shaped) will give different Heat transfer and friction characteristics. Han and Zhang (2000) carried out experiments to study the heat transfer and pressure drop characteristics of a roughened square channel with various angled and V-shaped broken rib arrangement with rib attack angle of $45^{\circ}$ and $60^{\circ}$, the Reynolds number was from 15000 to 90000 . They were reported that $60^{\circ} \mathrm{V}$-shaped broken rib arrangements give better performance than $45^{0}$ $\mathrm{V}$-shaped broken ribs. They also concluded that broken ribs create heat transfer enhancement level of 2.5 to 4, while the enhancement created by the continuous ribs is only 2 to 3 . Tanda (2004) investigated the heat transfer enhancement for one wall-ribbed rectangular channel of $A R=5: 1$ with continuous, $90^{\circ}$ and V-broken ribs and found that the enhancement of the $90^{\circ}$ broken ribs is around 1.8 times higher than that of continuous ribs. Han et al. (1991) presented experimental results on pressure drop and heat transfer in a square channel with ribs on two walls for nine different rib configurations. Regionally averaged heat transfer and friction factor were reported for rib pitch-to-height ratio $(p / e)$ of 10 and the rib height to hydraulic diameter $\left(e / D_{h}\right)$ of 0.0625 . They concluded that the angled ribs and ' $\mathrm{V}$ ' ribs provide higher heat transfer augmentation compared to continuous ribs. It was observed that the heat transfer augmentations and the friction factor were highest for the $60^{\circ}$ orientation compared to $45^{\circ}$ and $90^{\circ}$ orientation amongst the angled ribs. The $60^{\circ}$ ' $\mathrm{V}$ ' and $60^{\circ}$ ' $\Lambda$ ' offered higher heat transfer augmentation compared to the corresponding $45^{\circ}$ orientation. The crossed rib configuration offered least heat transfer augmentation. The friction factor was found to be highest for $60^{\circ}$ angled ribs compared to $45^{\circ}$ and $90^{\circ}$ configuration. Continuous rib configuration offered the least resistance and the $60^{\circ}$ ' $\Lambda$ ' case offered highest flow resistance among all configurations.

A very narrow channel $(A R=8: 1)$ with $V$-shaped, $\Lambda$-shaped, and angled ribs was studied by Gao and Suden (2001). Using a liquid crystal technique, they too confirmed that $\mathrm{V}$-shaped ribs result in the highest heat transfer enhancement and the highest frictional losses. They concluded that the V-shaped ribs yield the best overall thermal performance. Kim et al. (2001) also investigated heat transfer enhancement mechanisms in rectangular channels with $\mathrm{V}$ - and $\Lambda$ shaped ribs using a flow visualization technique to examine the secondary flow behaviours created by the V-shaped ribs. Taslim et al. (1996) experimentally investigated the heat transfer and friction in channel roughened with angled, V-shaped and discrete ribs on two opposite walls for Reynolds number ranging from 5,000 to 30,000. The results showed that the $90^{\circ}$ transverse ribs produced the lowest heat transfer performance. The $45^{\circ}$ angled $\mathrm{V}$-shaped ribs produced the highest heat transfer performance in comparison to other rib configurations. For V-shaped ribs facing downstream of flow, the one with lowest blockage ratio had better heat removal rate. The discrete ribs also produced better performance in comparison to the transverse ribs.

Muluwork et al. (1998) have investigated the effect of a staggered discrete V- apex up and down on the thermal performance. The Stanton number for $\mathrm{V}$-down discrete ribs was higher than the corresponding $\mathrm{V}$ upwards and transverse discrete roughened surfaces. The Stanton number ratio enhancement was found to be 1.32 to 2.47 in the range of parameters covered in the investigation. Further for the Stanton number, it was seen that the ribbed surface friction factor for V-downwards discrete ribs was highest among the three configurations investigated. Karwa (2003) has investigated and revealed the effect of transverse, inclined, V-continuous and V-discrete patterns on heat transfer and the friction factor in a rectangular duct. The ribs in the V-pattern were tested for both pointing upstream (V-upwards) and downstream (Vdownwards) to the flow. The angle of inclination of the ribs in inclined and V-pattern was $60^{\circ}$. The enhancement in the Stanton number over the smooth duct was up to $137 \%, 147 \%, 134 \%$ and $142 \%$ for the $\mathrm{V}$-up continuous, V-down continuous, V-up discrete and V-down discrete rib arrangement respectively. The friction factor ratio for these arrangements was up to 3.92, 3.65, 2.47 and 2.58, respectively. Based on the equal pumping power, $\mathrm{V}$-down discrete roughness gave the best heat transfer performance.

From above, it can be stated that inclined and V-shaped ribs when arranged in a systematic manner produces excessive enhancement in convective heat transfer, however the friction factor also increases. Some of the researchers investigated that $\mathrm{V}$-shaped ribs give higher heat transfer than $\Lambda$-shaped ribs, whereas, some observed the reverse results.

In the present work, experimental investigations have been carried out on an opposite side roughened square duct having artificial roughness in the form of $\mathrm{V}$ and $\Lambda$-shaped rib, to determine the enhancement in heat transfer and friction factor to find out which one give the highest heat transfer performance. The optimum value of rib attack angle $(\alpha)$ for both types ( $\mathrm{V}$ and $\Lambda$ - shaped) of ribs have been obtained and discussed.

\section{EXPERIMENTAL PROGRAM AND ROUGHNESS GEOMETRY}

A schematic diagram of the test set up is shown in Fig.1. which was used by Gupta et al. (2013) and Chaube et al. (2014). The wooden square duct has an internal size of $3750 \mathrm{~mm}$ x $75 \mathrm{~mm}$ x $75 \mathrm{~mm}$, which consists of an entrance section, a test section and an exit section of length $1500 \mathrm{~mm}\left(20 D_{h}\right), 1500 \mathrm{~mm}\left(20 D_{h}\right)$ and $750 \mathrm{~mm}\left(10 D_{h}\right)$ respectively. The exit end of the duct is connected to $81 \mathrm{~mm}$ internal diameter G. I. (galvanized iron) pipe provided with a calibrated orifice plate through a square to circular transition piece. The outside of entire set-up from inlet to the orifice plate, were covered with $25 \mathrm{~mm}$ thick thermocole (foamed polystyrene) sheet, so that the heat losses from the test section can be minimized.

The aluminium plates are used as test plates which are made by gluing square aluminium ribs $(4.5 \mathrm{~mm} \times 4.5 \mathrm{~mm})$ in a required distribution to serve as top and bottom ribbed walls of the test section. The plates are heated by means of separate heaters assembly, thus subjected to uniform heat flux of $0-1500 \mathrm{~W} / \mathrm{m}^{2}$. To measure mass flow rate of air through the duct, a calibrated orifice-meter is used which is connected with an inclined U-tube manometer with a control valve in the pipeline. Twenty thermocouples are affixed on backside of the test plate as shown in Fig. 2 to record the plate temperature at different 
locations. The bulk air temperature at the entrance section is measured by providing thermocouple at the entrance section, whereas bulk temperature of the air at the exit is recorded by three thermocouples mounted spanwise at the exit section after mixing (depthwise). To measure the pressure drop across the test section length a digital micromanometer (Fluke-922) is connected between the required points. The airflow rate was varied to give the flow having Reynolds number in the range of 10000 to 40,000 . Relevant data were noted under the steadystate condition for constant surface heat flux, which was assumed to have reached when the plate and air temperatures shows negligible variation for about 10- minute duration. The steady state for each test run was obtained in about 1.5 to 2 hours. In order to minimize the percentage error in measurement of temperatures, minimum heat flux value is so selected as to maintain the temperature of roughened plate around $20^{\circ} \mathrm{C}-30^{\circ} \mathrm{C}$ above to that of mean bulk air temperature.

The $\mathrm{V}$ and $\Lambda$-shaped ribs used in the investigation are shown in Fig. 3 . The relative roughness height $\left(e / D_{h}\right)$ and relative roughness pitch (p/e) are kept constant as 0.060 and 10 respectively. Reynolds number was varied in the range of 5000 to 40000 . Experimental data for both types of ribs were collected for attack angle $(\alpha)$ of $45^{\circ}$ and $60^{\circ}$.
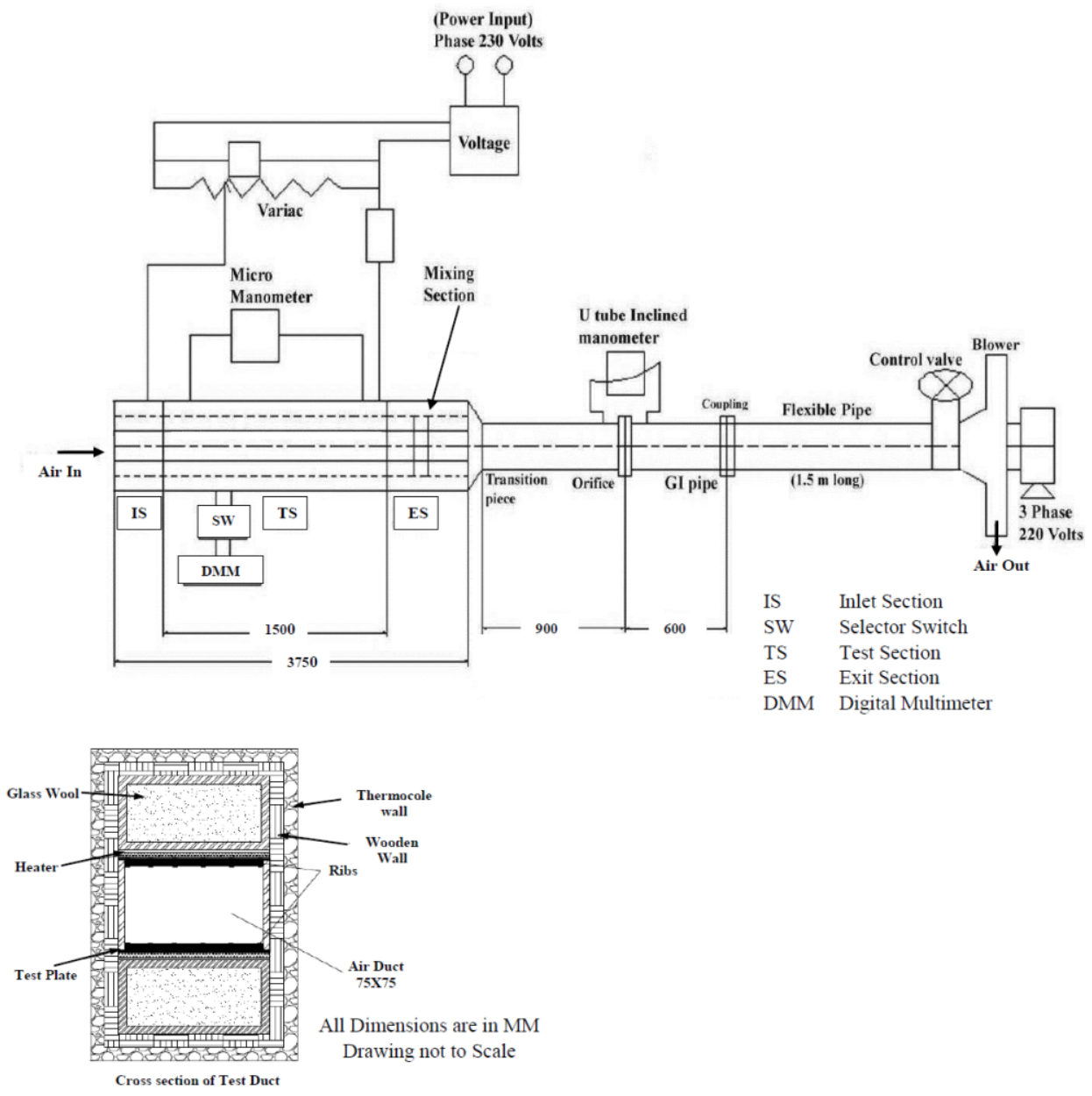

Fig. 1. Schematic diagram of experimental set-up

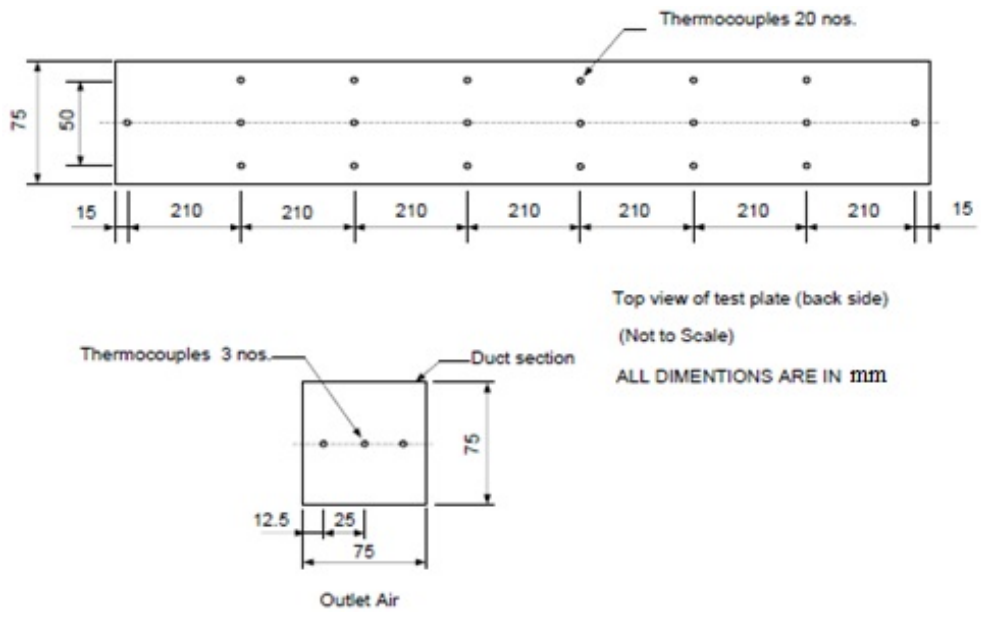

Fig. 2. Detailed locations of thermocouples 


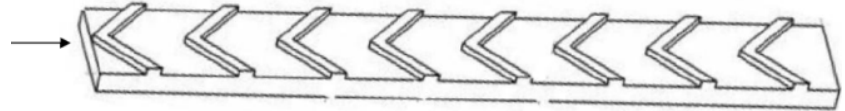

(a) V-shaped (V- upstream) rib

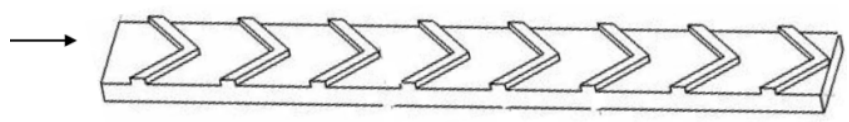

(b) $\Lambda$-shaped (V- downstream) rib

Fig. 3. Schematic of roughness geometry

\section{DATA REDUCTION}

The objective of this experiment is to investigate the Nusselt number and friction factor in the channel. The Reynolds number based on the channel hydraulic diameter, $D h$, is given by

$R e=\frac{\rho_{a} V D_{h}}{\mu_{a}}$

where, $\quad V=\frac{m}{\rho_{a} \cdot W \cdot H}$

The mass flow rate, $m$, of air through the duct has been calculated from pressure drop measurement across the orifice plate.

$$
m=C_{d} \cdot A_{o}\left[\frac{2 . \rho_{a} \cdot(\Delta P)_{o}}{1-\beta^{4}}\right]^{0.5}
$$

The pressure drop $(\Delta P)_{o}$ across the orifice plate is given by

$$
(\Delta P)_{o}=9.81 \times(\Delta h)_{o} \times \rho_{m} \times \sin \theta
$$

The average heat transfer coefficient, $h$, is evaluated from the measured temperatures and heat inputs. With heat added uniformly to fluid $\left(Q_{u}\right)$ and the temperature difference of plate and fluid $\left(T_{p}-T_{f}\right)$, the average heat transfer coefficient will be evaluated from the experimental data via the following equations:

$$
\begin{gathered}
Q_{u}=m C_{p}\left(T_{o}-T_{i}\right) \\
\boldsymbol{h}=\frac{Q_{\boldsymbol{u}}}{\boldsymbol{A}_{\boldsymbol{p}}\left(T_{\boldsymbol{p}}-T_{f}\right)}
\end{gathered}
$$

The average value of plate temperature $\left(T_{p}\right)$ is calculated as a weighted mean of the plate temperature measured at different locations and mean bulk air temperature $\left(T_{f}\right)$ is calculated from the following equations.

$$
\begin{gathered}
T_{f}=\frac{T_{i}+T_{o}}{2} \\
T_{p}=\sum_{n=1}^{20} \frac{T_{n}}{20}
\end{gathered}
$$

Then, average Nusselt number, $\mathrm{Nu}$, is written as

$$
N u=\frac{h D_{h}}{k_{a}}
$$

The friction factor is determined from the measured values of pressure drop, $(\Delta P)_{d}$ across the test section length, between the two points located $1.2 \mathrm{~m}$ apart.

$$
f=\frac{2(\Delta P)_{d} D_{h}}{4 \rho_{a} L_{f} V^{2}}
$$

where, $(\Delta P)_{d}$ is the pressure drop across the duct and is given by

$$
(\Delta P)_{d}=9.81 \times(\Delta h)_{d} \times \rho_{m}
$$

A parameter known as thermo-hydraulic performance parameter ' $\eta$ ' is used to evaluate the effectiveness of artificially roughened surfaces accounting for the enhancement of Nusselt number and friction factor [Lewis, M. J., 1975]. It can be calculated by

$$
\eta=\left[\left(N u_{r} / N u_{o}\right) /\left(f_{r} / f_{o}\right)^{1 / 3}\right]
$$

Based on the calculations of the errors in the experimental measurements by various instruments used, the uncertainties in the calculated values of Reynolds number, Nusselt number, friction factor and thermo-hydraulic performance parameter are estimated as $\pm 1.65 \%$, $1.94 \%, \pm 3.22 \%$ and $2.25 \%$ respectively (Holman, 2004).

\section{VALIDATION OF EXPERIMENTAL DATA}

Before taking the experimental data of artificially roughened ducts, the experimental set up was validated by keeping all surface as smooth surfaces and the results obtained in the form of Nusselt number and friction factor were compared with the standard correlations for Nusselt number and friction factor obtained with the standard Dittus-Boelter equation $\left(\mathrm{Nu}_{o}=0.023 \mathrm{Re}^{0.8} \mathrm{Pr}^{0.4}\right)$ for the Nusselt number and Blasius equation $\left(f_{o}=0.079 R e^{-0.25}\right)$ for friction factor (Bhatti and Shah 1987).

The comparison of the experimental and predicted values of Nusselt number and friction factor as a function of Reynolds number is shown in Fig.4 and in Fig. 5 respectively. It is observed that the average deviation between the predicted and experimental values has been $\pm 5.9 \%$ and $\pm 7.3 \%$ for Nusselt number and friction factor respectively. Thus the results obtained and the predicted values are in good agreement, which ensures the accuracy of the experimental data with the present experimental set-up.

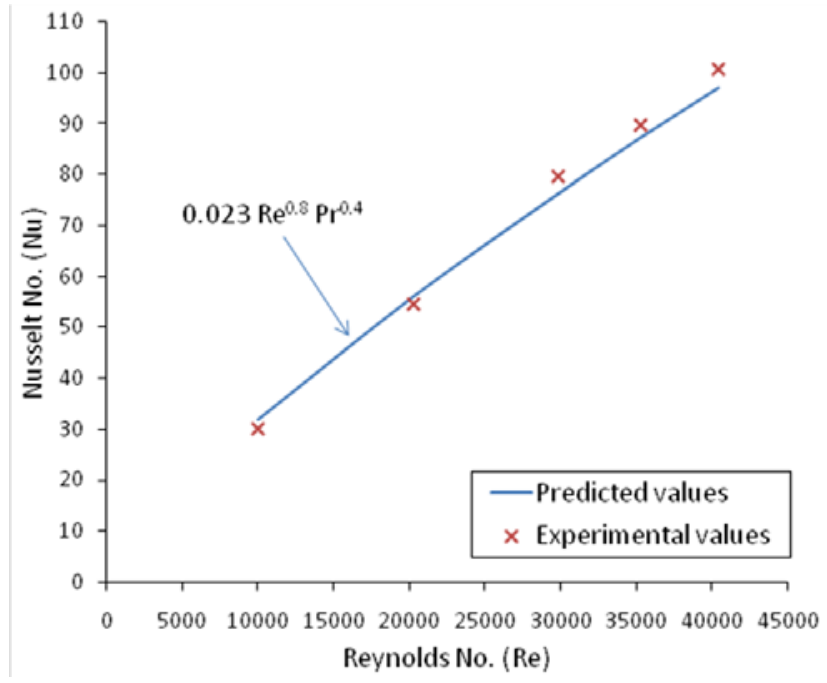

Fig. 4. Comparison of experimental and predicted values of Nusselt number for smooth duct 


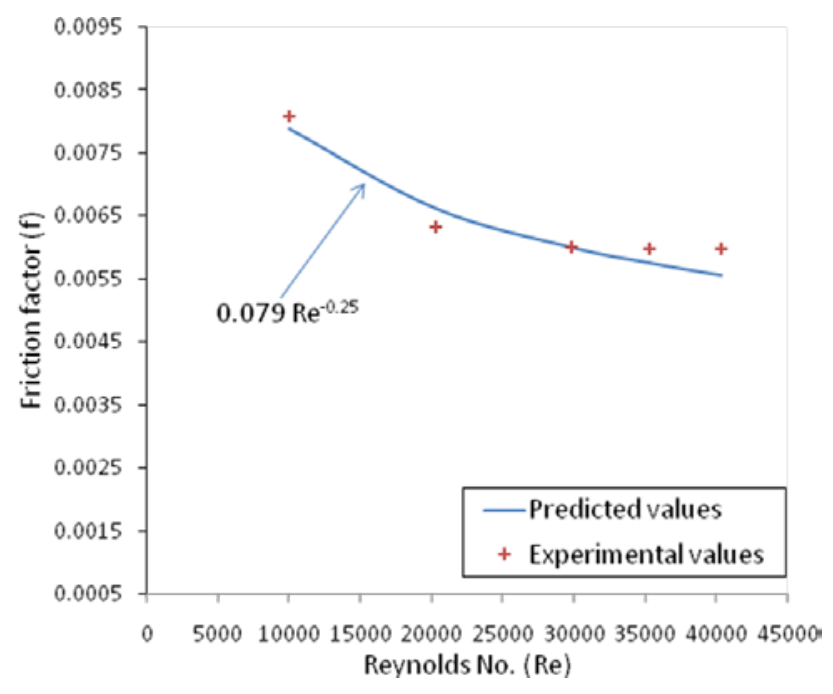

Fig. 5. Comparison of experimental and predicted values of friction factor for smooth duct

\section{RESULTS AND DISCUSSION}

The values of Nusselt number and friction factor for $\Lambda$-shaped and Vshaped rib geometry were computed on the basis of experimental data collected for various flow and roughness parameters. The effects of various parameters on Nusselt number and friction factor are presented in this section.

Figure 6 and Fig. 7 shows the values of Nusselt number, and Nusselt number ratio for $\mathrm{V}$-shaped ribs respectively. It is clear from the figures that the Nusselt number increases as Reynolds number increases and the heat transfer enhancement is about 2.75 to 3.8 times than that of smooth duct. The formation of secondary flow by the ribs is mainly responsible for the increase in heat transfer coefficient.

The V-shaped ribs are responsible for the spanwise heat transfer coefficient. Gao and Sunden [23] suggested the four cell pattern of secondary flow. The swirling motion created by the secondary flow helped to generate a high overall average heat transfer coefficient. The heat transfer enhancement is higher for rib attack angle $\alpha=60^{\circ}$ than $\alpha=45^{\circ}$. The flow travels along the ribs from side wall and meets at the apex of the rib whereas for V ribs the flow deflects from the apex and then travels along the ribs to generate secondary flows. (as shown in Figure 8).

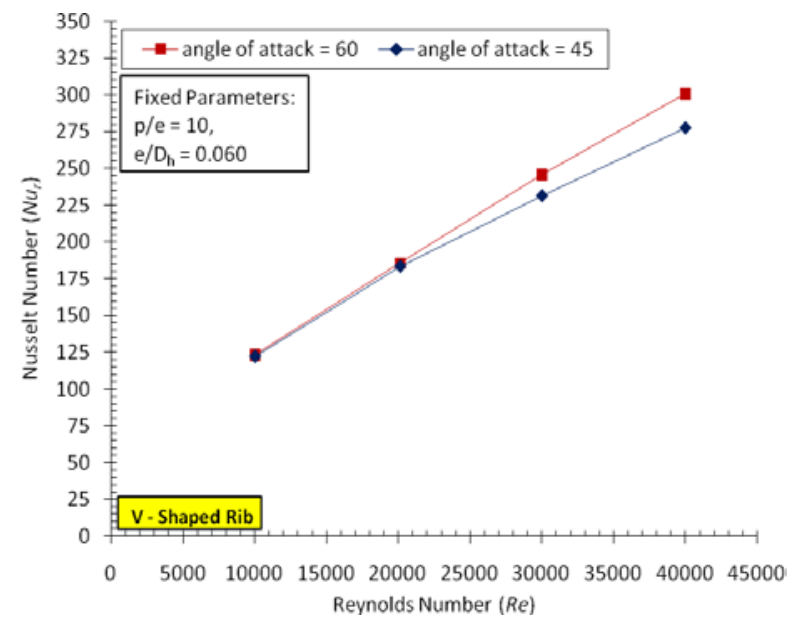

Fig. 6. Variation of Nusselt number with Reynolds number at $\alpha=60^{0}$ and $45^{\circ}$ for $\mathrm{V}$-shaped ribs.

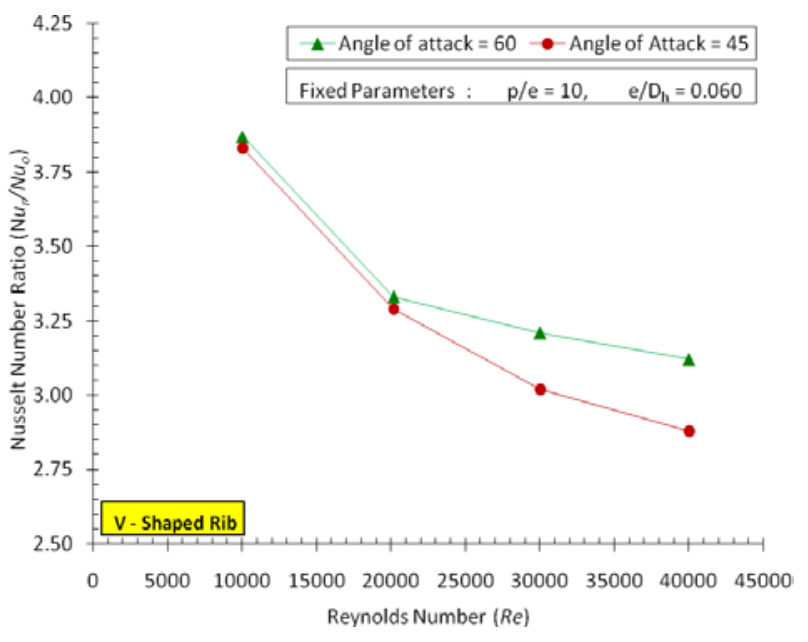

Fig. 7. Variation of Nusselt number ratio with Reynolds number at $\alpha=60^{\circ}$ and $45^{\circ}$ for $\mathrm{V}$-shaped ribs.
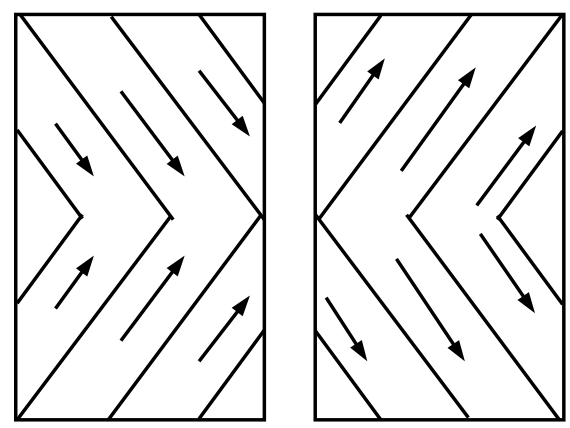

Fig. 8. Secondary flow generated in $\Lambda$-shaped and V-shaped ribs

Figure 9 and 10 illustrates the variation of friction factor with Reynolds number for different rib attack angles of V-shaped ribs. It is observed from Figures 9 and 10 that the friction factor decreases as Reynolds number increases and it remains almost constant at higher Reynolds numbers. The increase in friction factor ranges from 7 to 8.8. The friction factor enhancement is more for $60^{\circ}$ ribs as compared to $45^{0}$ ribs.

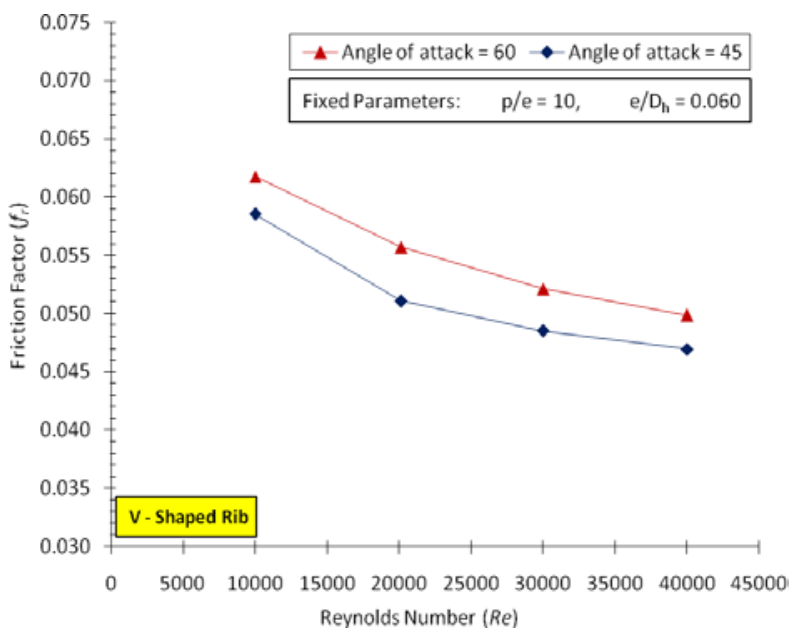

Fig. 9. Variation of friction factor with Reynolds number at $\alpha=60^{\circ}$ and $45^{0}$ for $\mathrm{V}$-shaped ribs. 


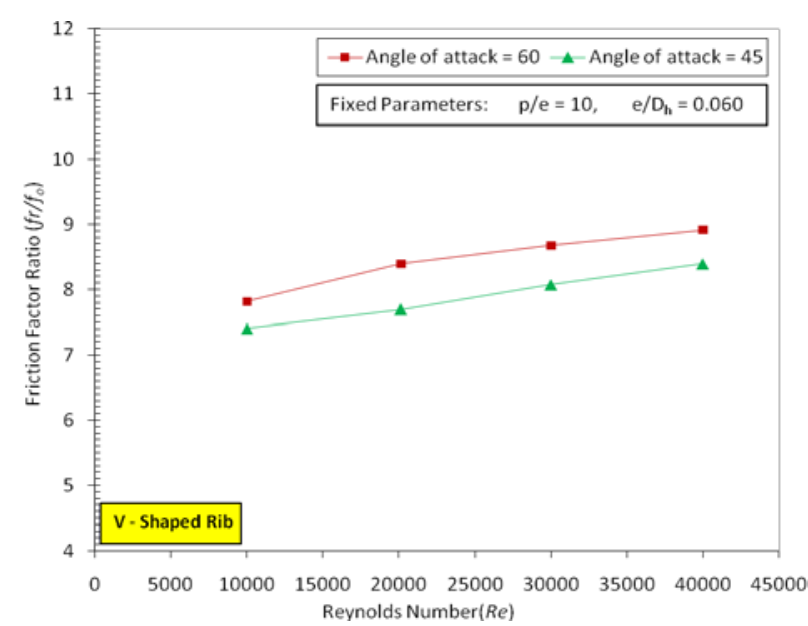

Fig. 10. Variation of friction factor ratio with Reynolds number at $\alpha=60^{\circ}$ and $45^{\circ}$ for $\mathrm{V}$-shaped ribs.

Figures 11 to 14 show the Nusselt number and friction factor results for $\mathrm{V}$ - ribs pointing downstream ( $\Lambda$ - shaped ribs). In contrast to the $\mathrm{V}$ the $\Lambda$ - shaped ribs produces less heat transfer and more friction factor. It is also observed that at low Reynolds numbers, the $\Lambda$-ribs produces lower heat transfer coefficient. It seems that a much weaker secondary flow is generated than the case of V-shaped ribs. Gao and sunden (2001) shows that in addition to the main flow V ribs also created two double cell counter rotating vortices but the direction is reversed as in the case of $\Lambda$-shaped ribs. Liou et al. (2000) investigated the secondary flow patterns for $45^{\circ} \mathrm{V}$-shaped ribs pointing upstream and downstream in a square duct. The results conforms the results of present investigation and but opposite results are observed as compared to the results of Gao and Sunden (2001). The reason is that the aspect ratio in present case is 1 which produces the different kind of secondary flow as compared to the rectangular ducts. The wall confinement reduces the regions where secondary flows are directed towards the bottom wall and therefore curtails the heat transfer enhancement for the case of $\mathrm{V}$ - ribs pointing downstream. The friction factor enhancement is also somewhat reduces as compared to the case of $\mathrm{V}$ ribs pointing upstream.

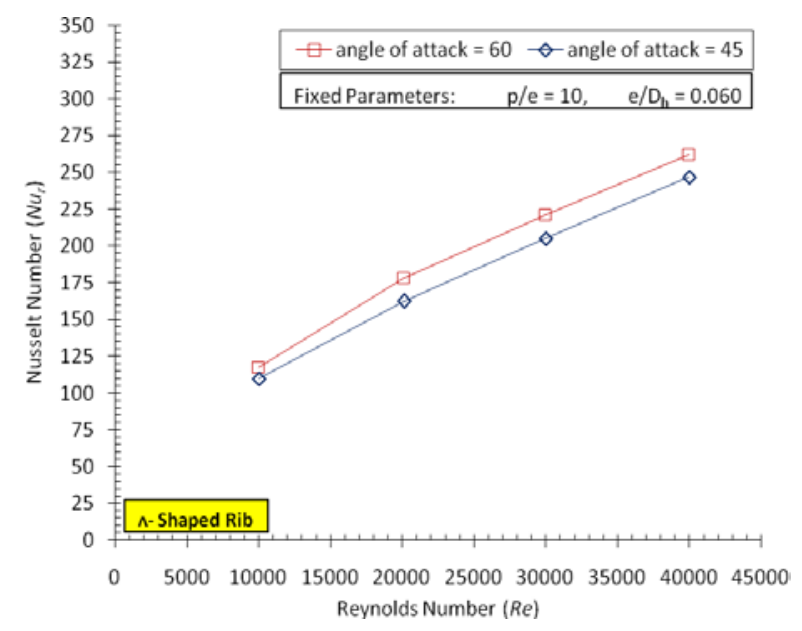

Fig. 11. Variation of Nusselt number with Reynolds number at $\alpha=60^{\circ}$ and $45^{\circ}$ for $\Lambda$-shaped ribs.

The $\Lambda$-shaped ribs produce less heat transfer whereas pressure penalty is greater than the $\mathrm{V}$-shaped ribs. Thus the best rib geometry can be decided by considering the heat transfer and friction characteristics simultaneously. A parameter that facilitates the simultaneous consideration of thermal and hydraulic performance known as thermo-hydraulic performance (Lewis, 1975) is evaluated for both the cases and plotted as in Figure 15. It is observed from the figure that the thermo hydraulic performance for V-shaped ribs is higher than the $\Lambda$-shaped ribs . For all the cases studied the performance is decreases as Reynolds number increases. V-shaped ribs with $\alpha=45^{\circ}$ give comparable results as compared to the results of $\mathrm{V}$-shaped ribs with $\alpha=60^{0}$.

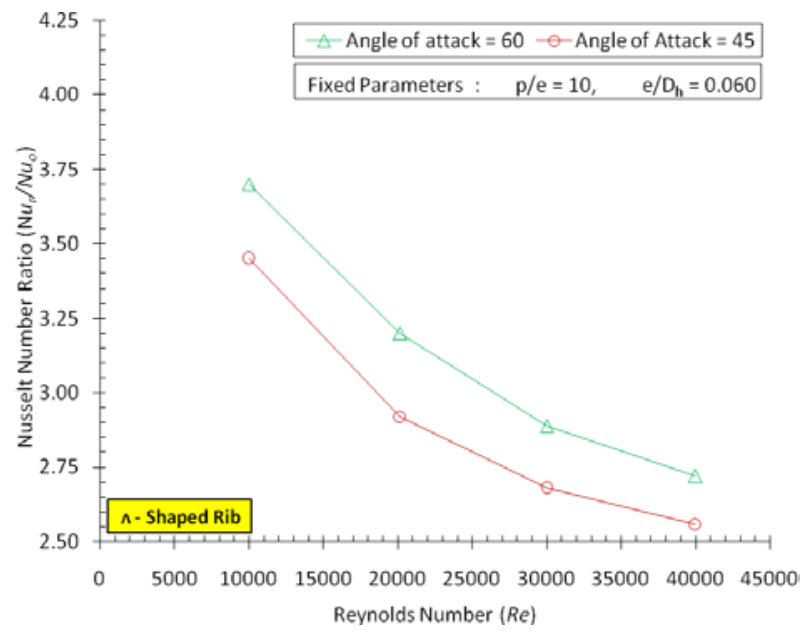

Fig. 12. Variation of Nusselt number ratio with Reynolds number at $\alpha=60^{\circ}$ and $45^{\circ}$ for $\Lambda$-shaped ribs.

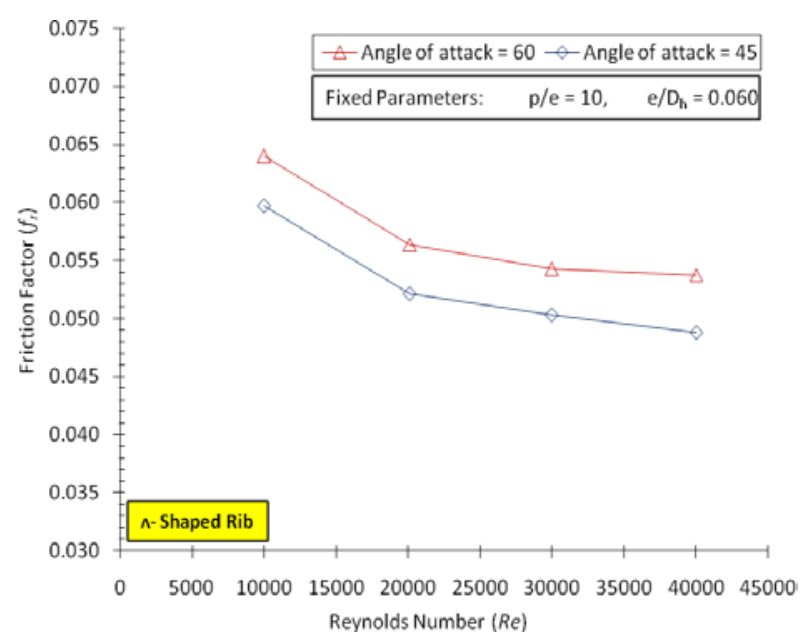

Fig. 13. Variation of friction factor with Reynolds number at $\alpha=60^{\circ}$ and $45^{\circ}$ for $\Lambda$-shaped ribs.

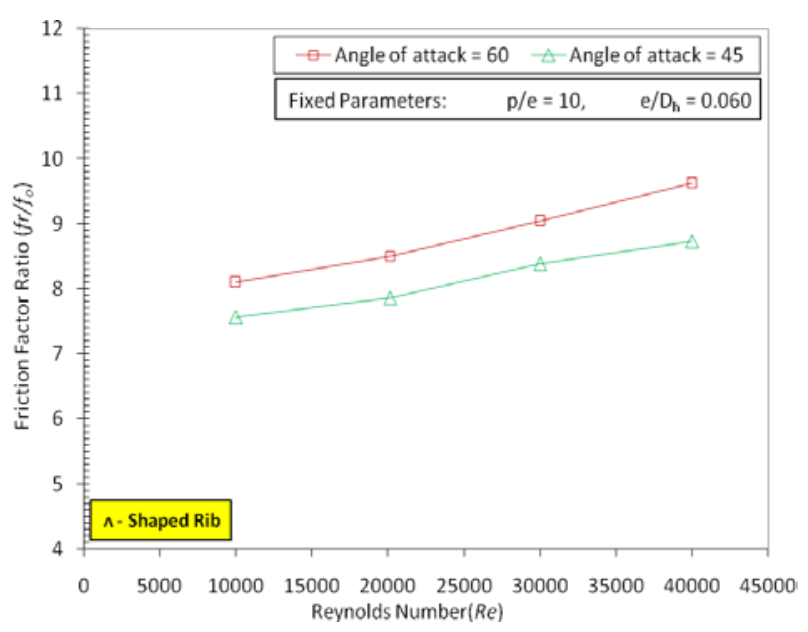

Fig. 14. Variation of friction factor ratio with Reynolds number at $\alpha=60^{\circ}$ and $45^{\circ}$ for $\Lambda$-shaped ribs. 


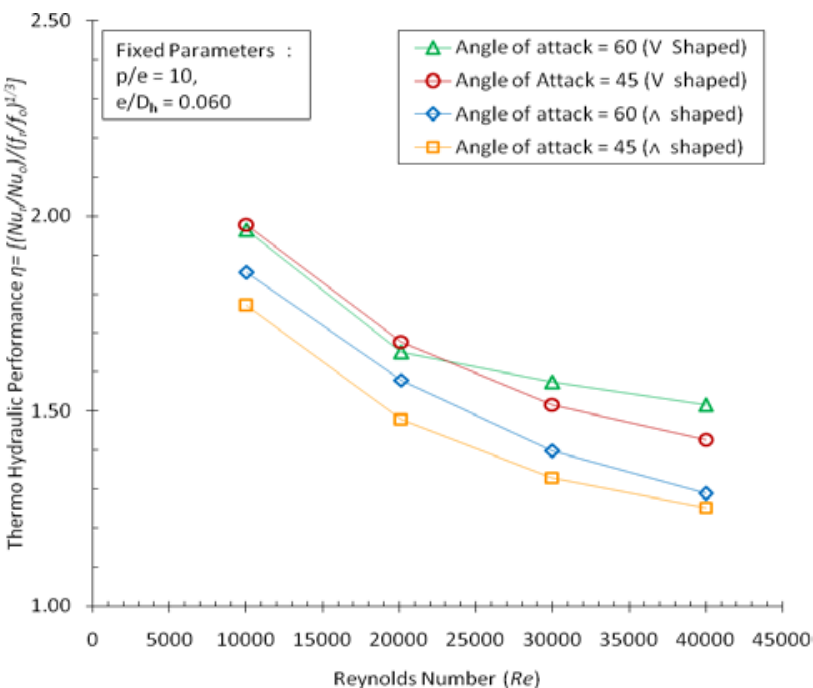

Fig. 15. Variation of Thermo hydraulic performance with Reynolds number at $\alpha=60^{\circ}$ and $45^{\circ}$ for $\mathrm{V}$ and $\Lambda$-shaped ribs.

\section{CONCLUSIONS}

An experimental investigation has been carried out with the aim to compare $\mathrm{V}$ and $\Lambda$-shaped rib geometry for a square duct to found out rib geometry that gives maximum heat transfer with high value of thermohydraulic performance.

The following conclusions can be drawn from this work:

(1) In general, Nusselt number increases and friction factor decreases with an increase of Reynolds number. Nusselt number and friction factor are significantly higher as compared to those obtained for smooth duct. This is due to the distinct change in the fluid flow characteristics as a result of $\mathrm{V}$ and $\Lambda$-shaped roughness that causes flow separations, reattachments and the generation of secondary flows.

(2) The Nusselt number enhancement decreases when the Reynolds number increases. The friction factor ratio is found to increases as Reynolds number increases and becomes constant at high Reynolds numbers.

(3) The maximum value of Nusselt number has been found for Vshaped ribs with $\alpha=60^{\circ}$ corresponds to relative roughness height $\left(e / D_{h}\right)$ of 0.06 and relative roughness pitch $(p / e)$ of 10 .

(4) The rib attack angle plays an important role for desirable fluid flow characteristics. The maximum value of Nusselt number for both the cases is obtained for $60^{\circ}$ due to stronger secondary flow.

(5) The maximum enhancement in Nusselt number and friction factor values compared to smooth duct are of the order of 3.8 and 8.8 respectively.

(6) The thermal performance decreases when the Reynolds number increases. The $\mathrm{V}$ shaped ribs with $\alpha=60^{\circ}$ give the highest thermal hydraulic performance for most of the Reynolds numbers. It produces somewhat less thermal hydraulic performance as compared to $\alpha=45^{0}$ for a narrow range of Reynolds number due to less value of friction factor at these Reynolds numbers.

(7) The $\mathrm{V}$ shaped ribs with $\alpha=45^{\circ}$ shows the comparable results as compared to the results of $\alpha=60^{\circ}$.

\section{NOMENCLATURE}

A Area of duct cross section, $\mathrm{m}^{2}$

$A_{p} \quad$ Area of roughened plate, $\mathrm{m}^{2}$

$A_{\text {pipe }} \quad$ cross section area of pipe, $\mathrm{m}^{2}$

$A R \quad$ Channel aspect ratio $(W / H)$

$C_{d} \quad$ Coefficient of discharge for orifice meter

$C_{p} \quad$ Specific heat of air at constant pressure, $\mathrm{J} / \mathrm{kg} \mathrm{K}$

$D_{h} \quad$ Channel hydraulic diameter of duct, $\mathrm{m}$

$\begin{array}{ll}D_{p} & \text { Inside diameter of pipe, m } \\ d / W & \text { Relative gap position } \\ e & \text { Rib height, m } \\ e / D_{h} & \text { Relative roughness height } \\ f & \text { Fanning friction factor } \\ f_{o} & \text { Friction factor for smooth circular duct } \\ f_{r} & \text { Friction factor for roughened duct } \\ f_{r} / f_{o} & \text { Friction factor ratio } \\ g / e & \text { Relative gap width } \\ H & \text { Depth of duct, m } \\ h & \text { Convective heat transfer coefficient, W/m }{ }^{2} \mathrm{~K} \\ k_{a} & \text { Thermal conductivity of air, W/m } \mathrm{K} \\ L & \text { Test section length, m } \\ L_{f} & \text { Duct length for calculation of friction factor, } \mathrm{m} \\ L / D h & \text { Test length to hydraulic diameter ratio } \\ m & \text { mass flow rate, kg/s } \\ N u & \text { Nusselt number } \\ N u_{o} & \text { Nusselt number for smooth circular duct } \\ N u_{r} & \text { Nusselt number for roughened duct } \\ N u_{r} / N u_{o} & \text { Nusselt number ratio } \\ p & \text { Rib pitch, m } \\ P r & \text { Prandtl number } \\ (\Delta P)_{d} & \text { Pressure drop in the test channel, N/m }{ }^{2} \\ (\Delta P)_{o} & \text { Pressure drop across the orifice plate, } \mathrm{N} / \mathrm{m}^{2} \\ p / e & \text { Relative roughness pitch } \\ Q u & \text { Useful Heat gain, W } \\ R e & \text { Reynolds number } \\ T_{f} & \text { Bulk mean air temperature, }{ }^{0} \mathrm{C} \text { or } \mathrm{K} \\ T_{i} & \text { Air inlet temperature, }{ }^{0} \mathrm{C} \text { or } \mathrm{K} \\ T_{o} & \text { Air outlet temperature, }{ }^{0} \mathrm{C} \text { or } \mathrm{K} \\ T_{p} & \text { Mean plate temperature, }{ }^{0} \mathrm{C} \text { or } \mathrm{K} \\ V & \text { Velocity of air, m/s } \\ W & \text { Width of duct, m } \\ & \end{array}$

Greek Symbols

$\alpha \quad$ Rib angle of attack, degree

$\beta \quad$ Ratio of orifice diameter to pipe diameter

$\theta \quad$ Angle of inclination of U-tube manometer, degree

$\mu_{a} \quad$ Dynamic viscosity of air, $\mathrm{N} \mathrm{s} \mathrm{m}^{-2}$

$\rho_{a} \quad$ Density of air, $\mathrm{kg} \mathrm{m}^{-3}$

$\rho_{m} \quad$ Density of manometer fluid, $\mathrm{kg} \mathrm{m}^{-3}$

\section{REFERENCES}

Bhatti, M. S., Shah, R. K., 1987, “Turbulent and Transition Flow Convective Heat Transfer," Handbook of Single-phase Convective Heat Transfer, Wiley, New York.

Chaube, A., Gupta, S. and Verma, P., 2014, "Heat Transfer and Friction Factor Enhancement in a Square Channel Having Integral Inclined Discrete Ribs on Two Opposite Walls,” Journal of Mechanical Science and Technology, 28 (5), 1927-1937.

http://dx.doi.org/10.1007/s12206-014-0143-1

Cho, H. H., Wu, S. J., and Kwon H. J., 2000, "Local Heat / Mass Transfer Measurements in a Rectangular Duct with Discrete Ribs," Journal of Turbomachinery, 122, 579-586.

http://dx.doi.org/10.1115/1.1303049

Gao X., and Sunden, B., 2001, "Heat Transfer and Pressure Drop Measurement in Rib-Roughened Rectangular Ducts," Journal of experimental thermal and fluid science, 24, 25-34.

http://dx.doi.org/10.1016/S0894-1777(00)00054-6

Gupta, S., Chaube, A. and Verma, P., 2013, “Augmented Heat Transfer in Square ducts with Transverse and Inclined Ribs with and without a gap,” International Journal of Current Engineering and Technology, 3(2), 688-694. 
Han J. C. and Park, J. S., 1988, "Developing Heat Transfer in Rectangular Channels with Rib Turbulators,” International Journal of Heat and Mass Transfer, 31, 183-195. http://dx.doi.org/10.1016/0017-9310(88)90235-9

Han, J. C. and Zhang, Y. M., 1992, "High Performance Heat Transfer Ducts with Parallel and V-Shaped Broken Ribs,” International Journal of Heat and Mass Transfer 35, 513-523.

http://dx.doi.org/10.1016/0017-9310(92)90286-2

Han, J. C. Glicksman, L. R. and Rohsenow, W. M., 1978, “An Investigation of Heat Transfer and Friction for Rib-Roughened Surfaces," International Journal of Heat and Mass Transfer, 21, 11431156.

http://dx.doi.org/10.1016/0017-9310(78)90113-8

Han, J. C., Dutta, S. and Ekkad, S. V., 2001, Gas Turbine Heat Transfer and Cooling Technology, Taylor \& Francis, Inc., New York.

Han, J. C., Zhang, Y. M., Lee, C. P., 1991, “Augmented Heat Transfer in Square Channels with Parallel, Crossed and V-shaped Angled Ribs,” Journal of Heat Transfer, 113, 590-596. http://dx.doi.org/10.1115/1.2910606

Holman, J. P., 2004, Experimental Methods for Engineers, Tata McGraw Hills, New Delhi.

Karwa, R., 2003, "Experimental Studies of Augmented Heat Transfer and Friction in Asymmetrically Heated Rectangular Ducts with Ribs on the Heated Wall in Transverse, Inclined, V-continuous And V-discrete Pattern,” Int. Comm. Heat Mass Transfer, 30, 241-250.

http://dx.doi.org/10.1016/S0735-1933(03)00035-6

Kiml, R., Mochizuki, S, and Murata, A., 2001, "Heat Transfer Enhancement Mechanism in a Rectangular Passage with $\mathrm{V}$ and $\Lambda$ Shaped Ribs,” J. Flow Visualization Image Process, 8, 51-68.

Kiml, R., Mochizuki, S., Murata, A., 2001 "Effects of Rib Arrangements on Heat Transfer and Flow Behavior in a Rectangular Rib Roughened Passage,” Journal of heat transfer, 123 (4), 675-681. http://dx.doi.org/10.1115/1.1378019

Lau, S. C., Kukreja, R. T., McMillin, R.D., 1991, “Effects of V-shaped Rib Arrays on Turbulent Heat Transfer and Friction of Fully Developed Flow in a Square Channel," Int. Journal of Heat and Mass Transfer, 34 (7), 1605-1616.
http://dx.doi.org/10.1016/0017-9310(91)90140-A

Lau, S. C., McMillin R. D., and Han, J. C., 1991, "Heat Transfer characteristics of turbulent flow in a square channel with angled rib", Journal of Turbomachinery, 113, 367-374. http://dx.doi.org/10.1115/1.2927885

Lewis, M. J., 1975, "Optimizing the thermo-hydraulic performance of rough surfaces," international Journal of Heat and Mass transfer, 18, 1243-1248.

http://dx.doi.org/10.1016/0017-9310(75)90232-X

Liou T., and Hwang, D., 1992, “Turbulent Heat Transfer Augmentation and Friction in Periodic Fully Developed Channel Flows,” Journal of Heat Transfer, 114, 56-64. http://dx.doi.org/10.1115/1.2911267

Liou, T. M., Chen, C. C., Tsai, T. W., 2000, "Heat transfer and fluid flow in a square duct with different shaped vortex generators,” Journal of Heat Transfer, 122 (2), 327-335.

http://dx.doi.org/10.1115/1.521487

Liou, T. M., Hwang, J .J., 1993, “Effect of ridge shapes on turbulent heat transfer and friction in a rectangular channel," International Journal of Heat and Mass Transfer, 36, 931-940. http://dx.doi.org/10.1016/S0017-9310(05)80277-7

Metzger, D. E. Fan, C. S., Yu, Y., 1990, "Effects of Rib Angle and Orientation on Local Heat Transfer in Square Channels With Angled Roughness Ribs,” Compact Heat Exchangers, Hemisphere, Washington.

Muluwork, K. B., Saini J. S., and Solanki, S. C., 1998, "Studies on discrete RIB roughened solar air heater, In: Proceedings of National Solar Energy Convention, Roorkee, 75 -84.

Tanda, G., 2004, "Heat Transfer in Rectangular Channel with Transverse and V-shaped Broken Ribs,” International Journal of Heat and Mass Transfer, 47, 229-243. http://dx.doi.org/10.1016/S0017-9310(03)00414-9

Taslim, M. E., Li, T. and Kercher, T. M., 1996, "Experimental Heat Transfer and Friction in Channel Roughened with Angled, V-Shaped and Discrete Ribs on Two Opposite Walls," ASME Journal of Turbomachinery, 118, 20-28. http://dx.doi.org/10.1115/1.2836602 